\title{
MONOTONICITY PATTERNS AND FUNCTIONAL INEQUALITIES FOR CLASSICAL AND GENERALIZED WRIGHT FUNCTIONS
}

\author{
KHALED MEHREZ
}

Abstract. Our aim in this paper is to present the completely monotonicity and convexity properties for the Wright function. As a consequences of these results, we present some functional inequalities. Moreover, we derive the monotonicity and log-convexity results for the generalized Wright functions. As applications, we present several new inequalities (like Turán type inequalities) and we prove some geometric properties for the four-parametric Mittag-Leffler functions.

Mathematics subject classification (2010): 33C20, 33E12, 26 D07.

Keywords and phrases: Wright function, generalized Wright function, four-parametric Mittag-Leffler function, complete monotonicity, Turán type inequalities.

Acknowledgement. The authors wish to acknowledge the referee comments and suggestions which enhanced this paper.

\section{REFERENCES}

[1] GD. Anderson, MK. Vamanamurthy, M. Vuorinen, Inequalities for quasiconformal mappings in space, Pac. J. Math. 160 (1) (1993) 1-18.

[2] M. El-Shahed, A. SAlem, An Extension of Wright Function and its Properties, Journal of Mathematics, Volume 2015, Article ID 950728, 11 pages.

[3] C. H. Kimberling, A probabilistic interpretation of complete monotonicity, Aequationes Math. 10, (1974), 152-164.

[4] K. MehreZ, New Integral representations for the Fox-Wright functions and its applications, J. Math. Anal. Appl. 468 (2018), 650-673.

[5] K. MenreZ, Functional inequalities for Wright functions, Integral Trans. Special Funct., 28 (2) (2017), 130-144.

[6] K. MehreZ, S. M. SitniK, Generalized Volterra functions, its integral representations and applications to the Mathieu-type series, Applied Mathematics and Computation, 347 (2019), 578-589.

[7] K. Mehrez, S. M. Sitnik, Functional inequalities for the Mittag-Lefler functions, Results in Mathematics, 72 (1) (2017), 703-714.

[8] K. MenreZ, S. M. SitniK, Turán type inequalities for classical and generalized Mittag-Leffler functions, Analysis Math. 44 (4), (2018), 521-541.

[9] K. MehreZ, S. M. SiTNIK, Monotonicity properties and functional inequalities for the Volterra and incomplete Volterra functions, Integral Transforms and Special Functions, 29 (11), (2018), 875-892.

[10] K. Mehrez, S. M. Sitnik, Functional inequalities for the Fox-Wright functions, Ramanujan J. (2018). https://doi.org/10.1007/s11139-018-0071-2.

[11] K. MehreZ, P. Agarwal, New Hermite-Hadamard type integral inequalities for convex functions and their applications, Journal of Computational and Applied Mathematics, 350 (2019), 274-285.

[12] D. S. Mitrinović, Analytic Inequalities, Springer-Verlag, Berlin, 1970.

[13] H. M. Srivastava, K. Mehrez, Ž. Tomovs Ki, New Inequalities for Some Generalized Mathieutype-series and the Riemann Zeta Function, Journal of Mathematical Inequalities, 12 (1) (2018), 163174. 
[14] T. K. Pogány, H. M. SRIVAStaVA, Some Mathieu-type series associated with the Fox-Wright function, Comput. Math. Appl. 57 (1) (2009), 127-140.

[15] Ž. Tomovs KI, K. MeHrez, Some families of generalized Mathieu-type power series, associated probability distributions and related functional inequalities involving complete monotonicity and logconvexity, Math. Inequal. Appl. (20) (2017), 973-986.

[16] D. V. WidDER, The Laplace Transform, Princeton Univ. Press, Princeton, 1941. 